Analéctica del lamento. La

sensibilidad como

germen de praxis

Alan Quezada Figueroa 


\section{Analéctica del lamento. La sensibilidad como germen de praxis}

\section{Analectic of lament. The sensitivity as a praxis germ}

Alan Quezada Figueroa

Doctorante en Filosofía

Universidad de Guanajuato

Miembro de la Asociación Mexicana de

Estudios en Estética y de la Asociación de

Filosofía y Liberación

Docente en la Escuela Nacional de Danza

Folklórica del INBA

ORCID. 0000-0003-2764-9785

filosofialan@gmail.com

(c) (1) (5) (2) Copyright $(2017$ UNAN-Managua

\section{RESUMEN}

El lamento es un fenómeno muy presente en nuestra cotidianidad; sin embargo, su vasta presencia implica también su trivialización, es decir, que de pronto resulte inaudible y quien se lamente sea invisible para los demás. El lamento solo afecta cuando es propio o de un ser amado. Si bien, dicho fenómeno es sobre todo un objeto estético, en tanto que manifiesta una sensación de malestar, dolor o desagrado, quiere decir que la actual es una sociedad anestesiada, o bien, insensible ante el dolor de los demás. Lo anterior hace posible que a los dirigentes de nuestras naciones latinoamericanas se les facilite más la tarea de llevar a cabo sus administraciones violentas, mediante los recursos necropolíticos, se administra a los cuerpos y sus muertes, para lograr un control más abarcante. De esta manera es que se vuelve necesario un modo para comunicar el dolor del otro y así volver a sensibilizarnos, como un principio de trasformación social y política, de superación de las condiciones críticas de miseria en las que viven nuestros pueblos. Para tal fin, se propone el concepto desarrollado por Enrique Dussel: analéctica, que lleva sobre todo una carga ética en la que se pueda generar un diálogo que privilegia la escucha, es decir que ya no es dialéctico negativo, sino que es abierto e integrador y siempre con pretensión de bondad. El sujeto que tiene una actitud analéctica tiene la capacidad para escuchar al otro desde su opresión y genera en sí mismo la responsabilidad de preservar su vida y su seguridad como principio colectivo de colaboración. Es preciso que, para desarrollar una política favorable para nuestras condiciones como pueblos latinoamericanos, debamos primero transformar y agudizar nuestras potencias sensibles, es decir, estéticas. Si la política siempre refiere al otro como componente de mi propia realidad, es preciso aprender a escuchar sus necesidades, y un principio de este aprendizaje en las condiciones actuales, es el lamento.

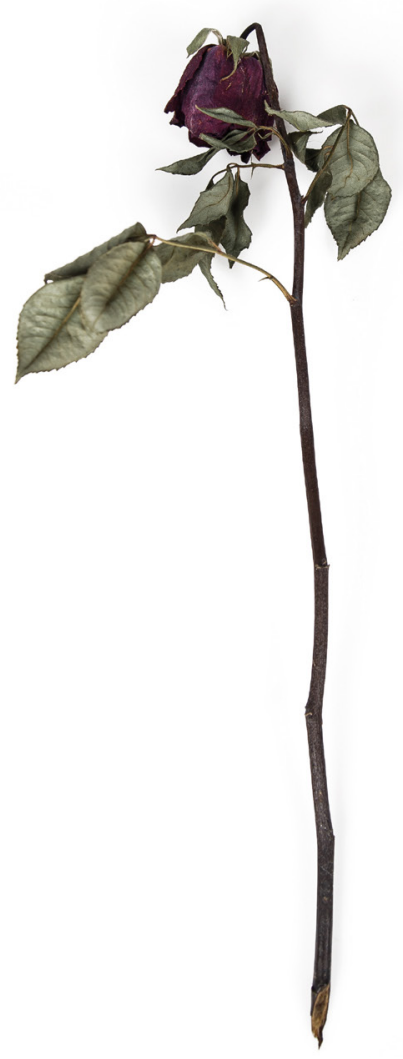

\section{PALABRAS CLAVE}

Analéctica, filosofía de la liberación, sensibilidad, estética, lamento. 


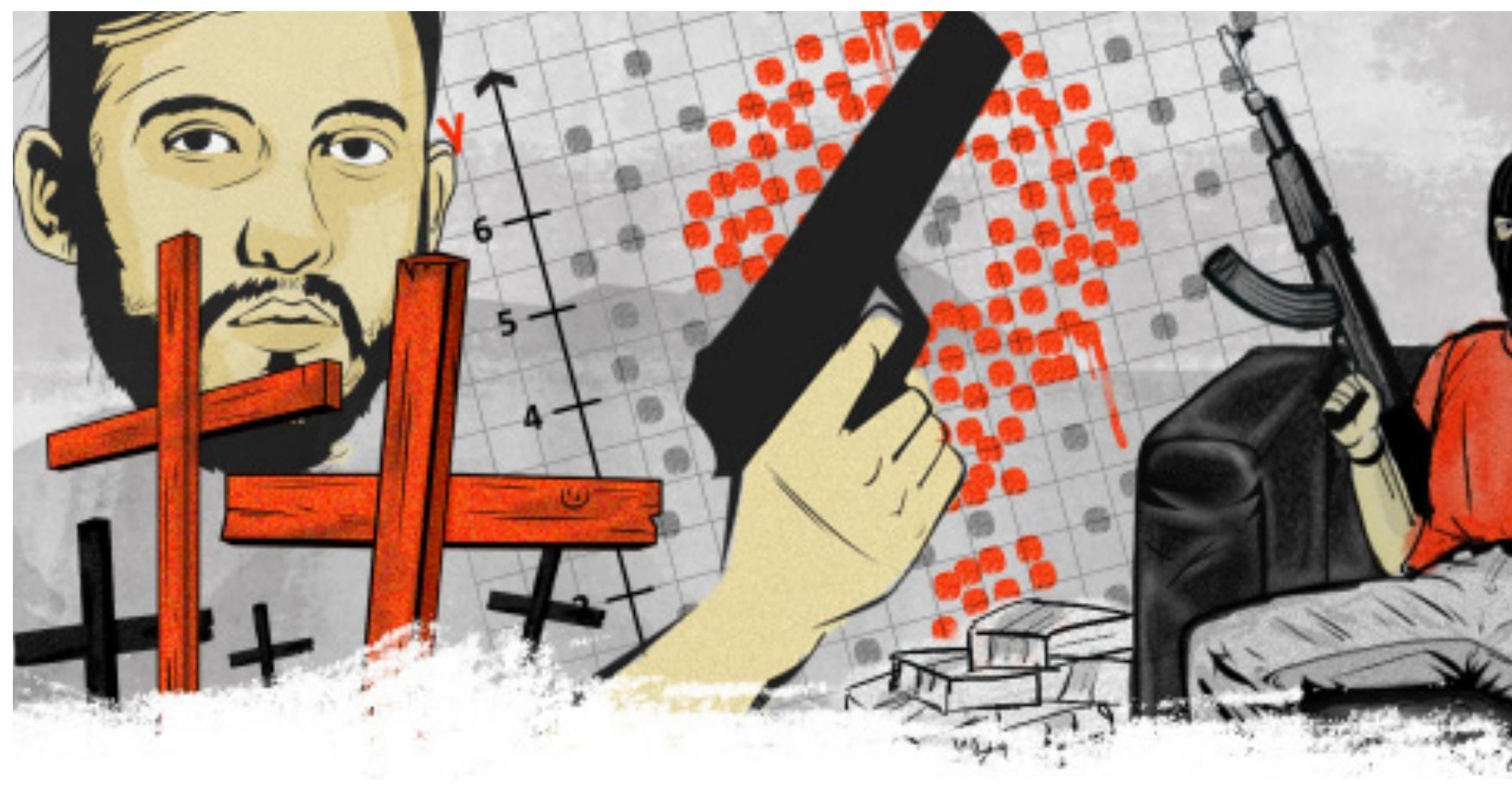

\section{ABSTRACT}

The lament is a phenomenon which is present in our daily life. However, its extensive presence also implies its trivialization, because suddenly can be inaudible and who are lamenting is invisible for others. The lament only affects when it is own or this is suffered by a person loved. While this phenomenon is above all an esthetic object, because expresses a discomfort sensation, pain or displeasure, it means this is an anesthetized society or it is insensitive to the pain of others. This allow to Latin American nations authorities do easy tasks, and they can carry out their violent administrations through the necropolitical resources, it is administered to bodies and their deaths, to achieve a more comprehensive control. In this manner, it is necessary a way to communicate the pain of other and re-sensitize us as a social and political transformation principle, for overcoming the critical conditions of misery in which our peoples live. For this purpose, it is proposed the Enrique Dussell concept: analectic, which takes above all an ethical burden in which a dialogue can be generated that privileges listening, which means it is no longer a negative dialectic, but rather that it is open and integrated and always pretending the goodness. The subject that has an analectic attitude has the capacity to listen to other from his oppression and generates in itself the responsibility to preserve his life and his safety, as a collective principle of collaboration. In this context, to develop a favorable policy to our conditions as Latin America peoples, it is necessary to transform and sharpen our sensitive powers, that is, esthetics. If the policy always refers to the other as a component of my own reality, it is necessary to learn to listen their needs, and a principle of this learning in the current conditions is the lament.

\section{KEY WORDS}

Analectic, liberation philosophy, sensitivity, esthetics, lament. 


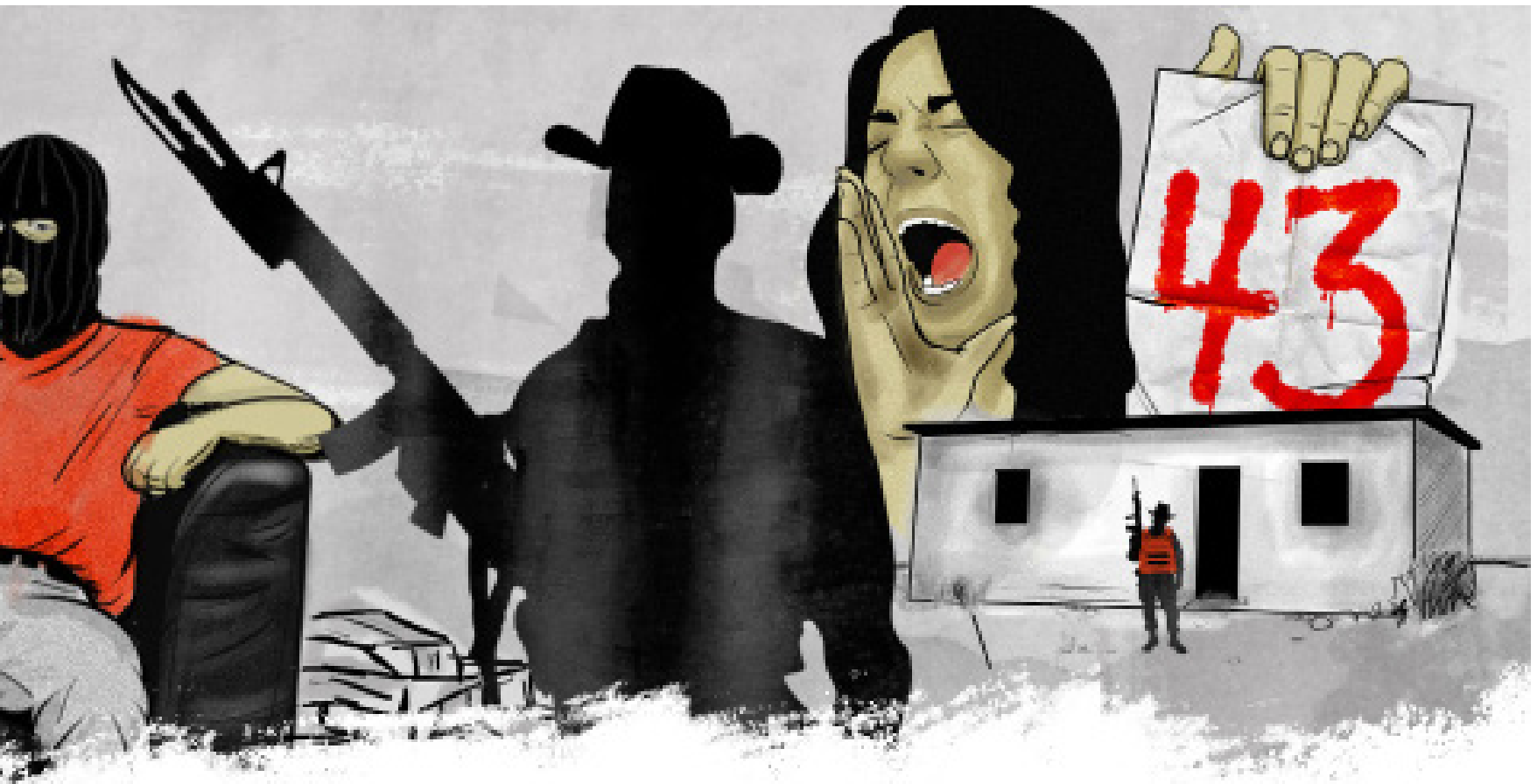

\section{Introducción}

ómo comenzar este recorrido de escritura, si el tema que se pretende analizar tiene una gran multiplicidad de expresiones que apuntan a una tímida demanda. Todo lamento tiene como epicentro una demanda, porque se trata de la materialización de una falta, de un estado indeseable en el que se encuentra alejado quien la profiere. Reconocemos el popular lamento que nos han inculcado a través de las leyendas de herencia colonial: ese "¡Ay mis hijos!" que no puede más que reclamar su presencia, demanda la vida de los que ya no están más; su ausencia no es otra cosa más que la causa de este lamento. Así como diferentes pueden ser las causas, diferentes pueden ser los lamentos que se profieren; de este modo es que nos interpelan por la vía sensible.

Vittorio de Sica nos traduce magistralmente el lamento de un padre angustiado a imágenes cinematográficas en su película El ladrón de bicicletas (1948). Antonio lamenta su miseria, solo busca una oportunidad para trabajar y mantener a su familia. El trabajo que logra conseguir le implica el uso de una bicicleta como herramienta de trabajo; no mucho tiempo después de conseguirla le es arrebata por un delincuente. Así transcurre la travesía por la que Antonio y su hijo Bruno intentan recuperar el vehículo sin ningún éxito. Antonio lamenta la triste expresión de su pequeño causada por la miseria de una Italia de la posguerra. Él exige justicia, pero en su lugar obtiene el desprecio de algunos transeúntes, quienes lo miran con desdén al caer en el recurso de la delincuencia con el fin de obtener una bicicleta y con ello garantizar la supervivencia de su familia.

Víctor Jara se lamentaba en cantos: "el hombre puede ser hombre cuando camina derecho", decía en una de sus canciones mientras buscaba transmitir a los demás la necesidad de ese reclamo que exige el reconocimiento de la dignidad humana, una exigencia de justicia y de igualdad; la consecuencia de sus lamentos fue la pena de muerte dictada ilegítimamente por los administradores de la miseria. Jara encontró la muerte más injusta a través de la tortura y el salvajismo de sus verdugos; sin embargo, nunca desistió y hasta el último minuto conservó 
su dignidad como humano. Hasta el día de hoy en su canto va la condena de tantos y tantos desaparecidos chilenos y del mundo. Eduardo Galeano escribió sus lamentos, grandes obras que denuncian el enriquecimiento de pocos mediante el empobrecimiento, la muerte y el dolor de los más. Esas letras condenan el asesinato sistemático de quienes llevaron la penitencia al haber nacido en medio de la riqueza, que fue la misma causa de su pobreza. Víctimas de la monstruosidad de los metales preciosos y del mecanismo de saqueo que se manifestaba en las minas de América Latina.

Estos y otros tantos voceros de la justicia y la solidaridad valiente no hicieron más que exponer de alguna manera los dolores humanos causados por la injusticia. ¿Cómo expresar con justicia el lamento o el inevitable dolor? El "¡Ay!" de La Llorona es apenas un medio para hacer reconocible - en la escritura o en la oralidad - un estado de lamentación.

La expresión de una persona que está - literalmente- muriendo por hambre, puede ir desde el alarido como reflejo del dolor hasta el gesto de llevar las manos hacia el estómago, como si con ello se conservara la esperanza de conseguir un alivio; se manifiestan también lágrimas de desesperación que van trazando mediante dibujos húmedos, el sufrimiento en las mejillas; la frente también se frunce, $y$ aparece un rostro que vacila entre la tristeza y el temor. ¿Es éste el acercamiento a la muerte? ¿Quién está preparado para este momento? Se trata del sendero del padecimiento que conduce a la muerte.

Todos esos gestos son el reclamo de una persona que quisiera conservar su vida, su reclamo es por alimento y, más profundamente, por justicia. Su reclamo no es consciente, es solo para el interpelado, para el con-vocado (Dussel, 2016) o bien el llamado al mesías al que aludía Walter Benjamin $-y$ al que volveré más adelante-. En suma, puede decirse que el lamento es el reclamo legitimado de una carencia, ya sea que ésta refiera a la salud, el alimento, la vida, el dinero, la felicidad, etc. Es decir, el lamento no puede surgir más que de la negatividad, de esas mismas condiciones que sitúan al otro en el rincón de la exterioridad o bien, en el papel de víctima.

Se trata de una reacción del cuerpo mismo, que significa el rechazo de la situación actual de negatividad. Nadie se lamenta de la felicidad, al menos no en acto. El alarido del hambriento es el último recurso para comunicar su padecimiento, para hacer visibles las úlceras sangrantes que le desgarran el estómago y que no se perciben desde fuera; se manifiesta también la debilidad y el mareo que lo des sitúan de la dignidad humana.

\section{Analéctica del lamento como expresión social}

El lamento es función estética que las demás especies animales poseen, tal como lo expresa Katya Mandoky con relación a una estética evolucionista, como una estética desde abajo, desde el cuerpo. Al respecto menciona: "Llevamos la estética en todo el cuerpo: en los sentidos, emociones y preferencias a lo largo y ancho de nuestra evolución." $(2013,10)$. Es entonces que podríamos entender el proceso del lamento como un proceso bioestético que tiene lugar en la necesidad de preservar la vida, toda vez que sea puesta en riesgo por las condiciones negativas que la asolan.

La violencia contra las mujeres que azota a México, ha generado que miles de ellas se solidaricen y salgan a las calles a exigir respeto para sus vidas, a manifestar su dignidad. Se trata de lamentos de quienes quisieran de vuelta a sus congéneres. La situación en toda América Latina es lamentable respecto del número de feminicidios que han tenido lugar. Es vergonzoso tener que recurrir a las cifras para poder comprender algo de la magnitud de la violencia que se

1 Es el que tiene la vocatio, como vocación y entonces es necesariamente interpelado. Tiene la vocación de escuchar y tomar responsabilidad por el otro. 
manifiesta en nuestros países. El asesinato de una sola debería ser, por sí mismo, un motivo de escándalo para nosotros. Se exige entonces la justicia para estas vidas humanas y la garantía de seguridad y respeto a la integridad de cada cuerpo y mente.

El ambiente de miedo y angustia pretende ser silenciado a partir de la difusión mediática que minimiza la catástrofe, mediante comentarios sosos y retrógrados, además de violentos, en los que se destaca el modo de vestir de las mujeres, que se han hallado sin vida o bien, los horarios en los que ocurrieron los hechos y la ingestión de bebidas alcohólicas, como si taparse y tener toque de queda garantizara su seguridad. Se busca hacer olvidar que se trata de seres humanos que tienen libertades y derechos que ni las instituciones, ni la sociedad civil, hemos hecho cumplir, porque no nos hemos enterado o querido enterar de que somos parte del problema.

Dicha actitud anestésica produce la disociación apresurada ante el dolor de las víctimas y de sus allegados, disgrega profundamente al sujeto de lo humano. La trivialización hace que el problema pierda las dimensiones de su importancia y se evite todo compadecimiento, es decir, que no se pueda padecer con el otro. Escapamos de la sensibilidad, como escapamos del abismo de la negatividad; es más cómodo alejarse del conflicto y apropiarse de la opinión que genera el discurso mediático mediocre.

Solo quien tiene la posibilidad de situarse en el caos, quien busca entender el lamento del hambriento y la consigna de la mujer violentada y amenazada, ese que intenta ir al origen y hacerse cargo de su responsabilidad, es el personaje histórico, es quien puede transformar la realidad, no así quien ha dado la espalda al conflicto y al dolor. Se trata de la figura del mesías. El mesianismo solo puede desarrollarse en la catástrofe, por lo cual el progreso nace mediante aquella. Es de este modo que se piensa en el lamento como el clímax material de la catástrofe, que busca desembocar en la interpelación -momento mismo del mesianismo, de quien ha reconocido la necesidad del oprimido en su demanda.

Llega entonces el momento de la praxis como el desarrollo de un acto de amor:

En la selva amazónica la primera mujer y el primer hombre se miraron con curiosidad. Era raro lo que tenían entre las piernas.

$-i$ Te han cortado? - preguntó el hombre.

-No - dijo ella-. Siempre he sido así

Él la examinó de cerca. Se rascó la cabeza. Ahí había una llaga abierta. Dijo:

-No comas yuca, ni guanábanas, ni ninguna fruta que se raje al madurar. Yo te curaré.

Échate en la hamaca y descansa.

Ella obedeció. Con paciencia tragó los mejunjes de hierbas y se dejó aplicar las pomadas y los ungüentos. Tenía que apretar los dientes para no reírse, cuando él le decía:

- No te preocupes.

El juego le gustaba, aunque ya empezaba a cansarse de vivir en ayunas y tendida en una hamaca. La memoria de las frutas le hacía agua la boca.

Una tarde el hombre llegó corriendo a través de la floresta. Daba saltos de euforia y gritaba:

- ¡Lo encontré! ¡Lo encontré!

Acababa de ver al mono curando a la mona en la copa de un árbol.

-Es así - dijo el hombre, aproximándose a la mujer.

Cuando terminó el largo abrazo, un aroma espeso, de flores y de frutas, invadió el aire. De los cuerpos, que yacían juntos, se desprendían vapores y fulgores jamás vistos, y era tanta su hermosura que se morían de vergüenza los soles y los dioses. (Galeano, 2016; 16) 
El personaje masculino fue interpelado por lo que entendía como una herida, esto hizo que se diera a la tarea de sanarla, en cuanto ello implica el progreso hacia la cura. Se trata indiscutiblemente de un acto de amor en el que está implicada una acción revolucionaria, en tanto se pone en marcha la acción para superar dicho estadio. Es así que cuando está implicada la violencia - legítima - se entiende como una violencia del amor (Freire, 2016), toda vez que se busque una superación de la violencia ejercida por el sistema y que era la que negaba al sujeto, convirtiéndolo en oprimido, tal como lo son las mujeres violentadas o las personas que pasan hambre, a quienes se aludió previamente. La violencia revolucionaria es la violencia más elevada para Benjamin, porque busca trascender su estatus y no perpetuarlo, es una violencia transitoria.

Es por ello que lo que aquí se pretende es incorporar (Mandoki) la teoría, es decir, llevar la teoría al cuerpo, de manera que resulta capital pensar en las corporalidades como portadores de una economía y una política que generan su propia forma de lectura a nivel de violencia. Los cuerpos más implicados e icónicos de un narcoestado ostentan cierta cartografía en la que se puede leer su nivel de opresión, víctimas de una ideología hipercapitalista que los ha llevado a aceptar la condición de peones en un tablero en el que juegan dos extremos del mismo bando: el Estado y el crimen organizado. La profanación de un cuerpo femenino en este territorio de violencia de género es también un indicador de la lógica de objetivación de la misma ideología: cuerpos que son medios para fines. El hambre en su siniestra brutalidad se manifiesta de manera más sutil, pues no tiene las marcas de la estrangulación o las heridas de bala que sí tienen los otros cuerpos referidos; se trata más bien de una degradación sistemática en la que cada vez el humano va tomando su forma de cadáver.

Hasta aquí he pensado en el papel de las víctimas, sin embargo, también se ha de pensar en el victimario, en tanto que interesa conocer su estatus estético-moral. Al respecto menciona Godard:

El único verdadero film que podría hacerse sobre (los campos de concentración) -que jamás se rodó y que no se rodará jamás porque sería intolerable- sería filmar un campo desde el punto de vista de los torturadores, con sus problemas cotidianos. ¿Cómo hacer entrar un cuerpo humano de dos metros en un féretro de cincuenta centímetros? ¿Cómo descargar diez toneladas de brazo y piernas en un vagón para sólo tres? ¿Cómo quemar cien mujeres con gasolina para diez? (...) Lo importante no sería el horror que destilarían tales escenas sino, muy por el contrario, su aspecto perfectamente normal y humano. (Citado en Benjamin, 2016, p.25).

¿Cómo es que estos asesinos han perdido, o suspendido todo regulador bioestético y moral con respecto a los otros? Unos cuantos se lamentan, en ocasiones dicen cosas como: "yo solo seguía órdenes". Es como si en ese acto de obediencia se desactivara un interruptor moral. ¿Qué sucede ahí con la potencia estética? Unos pocos han sido realmente sujetos históricos en tanto que han transformado la realidad - al negarse a seguir una orden que atentaría contra la vida humana. Esta es la actitud mesiánica que se halla escasamente en los episodios de genocidio que han tenido lugar alrededor del mundo. Las dictaduras latinoamericanas son casos lamentables de asesinatos en masa y desapariciones de luchadores sociales. Frente a eso se puede pensar que el interruptor moral se activa o se desactiva por la consciencia estética.

Existen objetos que, a pesar de inscribirse en el orden de lo cotidiano, llevan implicaciones sensibles devastadoras. En una de las cámaras del Museo de Memoria y Derechos Humanos en Santiago de Chile se halla un artefacto simple, como muchos otros, pero que trae consigo el significado de un gran dolor, de maneras complejas. La sala no contiene demasiados elementos, solo se halla una pantalla en la que se proyectan testimonios de sobrevivientes de la dictadura y a espaldas de esta, sin gran importancia, un documento encerrado en una urna acrílica transparente que servía como testimonio escrito. Pero el objeto que inmediatamente llama la atención es una cama de metal sin colchón conectada a una batería. 
No se hallan in situ demasiadas explicaciones, quizá ni siquiera hagan falta, la imaginación comienza a hacer una labor constructiva en la que busca dar cuenta, mediante la contextualización, de la razón de ser de tal objeto. Es tan imponente el elemento en cuestión resaltado por una iluminación caliente, dispuesto para ser contemplado y resultante del contraste con el salón negro y la oscuridad envolvente, que los demás objetos alrededor resultan menos notorios. A cuántas personas se les habrían extraído los más abrumadores alaridos mediante la tortura de descargas eléctricas que tendrían lugar en el mentado mueble. Un terrible procedimiento para borrar la memoria social y ética de quienes desfilaron por la frialdad de las barras metálicas que la componen. Con cuánto dolor se pagan los sueños de un mundo mejor y más justo.

Situarse frente a ese artefacto de tortura e imaginar ser uno mismo quien se adhiere a las funciones para las que fue creado, casi escuchar los gritos de dolor que de ahí surgieron e imaginar el abismo oscuro de la injusticia y la desesperanza que produjo por mucho tiempo, es la consecuencia empática de quien logra entender el significado de la razón dominante y sus técnicas de permanencia. Generador de intriga, de no saber ni cómo ni cuándo acabará, si ese mismo será su recorrido final. El miedo muestra su rostro más franco porque domina todo el panorama, se encuentra pleno en su elemento envolvente del espíritu.

Mientras, ¿qué ocurría con el operador de instrumento de tortura? Es aterrador pensar que para que tal evento sucediera, sería preciso que una mano humana activara una palanca. Es simple, solo se necesita una mano y la voluntad anestesiada para producir dolor en otro ser humano. ¿Quién es peor: el que no ha generado ningún tipo de reconocimiento en el sufrimiento de la víctima o el que se encuentra afectado por el dolor de esta víctima y sigue con el procedimiento inhumano? No se trata de cuantificar la violencia de los ejecutores - quienes a su vez tienen el temor de las consecuencias que conllevaría desobedecer órdenes y otras cuestiones de orden más complejo- sino de preguntarse por el lugar de la sensibilidad en aquellas condiciones límite del género humano. Es probable que la conversión de humano a máquina autista radique en la evaporación de la dimensión estética.

La salida de la sala de tortura del museo es una travesía sensible y dolorosa que inunda la cabeza de cuestionamientos y deja la piel bajo una sensación de frío, como si el propio cuerpo hubiese experimentado lo mismo que alguno de los que transitaron por aquella fría y desoladora plancha; los ánimos quedan también en negro como la sala misma que se ha abandonado. Salir a toda prisa no consigue que uno pueda escapar a la sensación de horror, asco y tristeza que se ha generado, al contrario, se sigue reproduciendo en la consciencia por un buen tiempo.

Es inevitable la cavilación profunda respecto de los demás. ¿Será que las otras personas que han salido de esa misma sala se encuentran igualmente afectados? Tremenda pregunta para la estética que a su vez debe incluir a los torturadores. Sin duda la función de aquel mueble expuesto es la generación de una conciencia ante los atroces hechos históricos, es claro también que no experimentamos exactamente los mismos sentimientos, aunque sí de manera similar. Pero sigue la complicación relativa a aquellos que pueden lastimar a los demás sin miramientos; sin dudas, ellos no experimentaron la misma sensación nauseabunda, ya que esto no les permitiría seguir adelante. Una cosa es clara: no lograron ser interpelados por el lamento de las víctimas, esos gritos quedaron vibrando atrapados en el tiempo y recorriendo las barras metálicas del artefacto.

El estatus sensible de los ejecutores se cuestiona a partir de su composición como corporalidad, como un cuerpo similar al del torturado o asesinado, y más aún, como sujeto que tiene lazos profundos con otras personas, sobre todo familiares. ¿Cómo es posible entonces lastimar a seres similares a sí mismos o a sus seres amados? ¿Cuál ha sido el componente que los ha dessensibilizado ante su propia naturaleza y los ha vuelto sordos ante el lamento del otro? Estas preguntas son las más comunes cuando se es testigo de la opresión del pueblo por una fracción del pueblo mismo - pero vestido de militar-, cuando su razón de ser es que se milite con las necesidades de la colectividad. 
La razón indolente es la que va carcomiendo las sensibilidades y comienza a parir sensibilidades autistas que solo actúan en función de sí mismas. Es así que se crean grupos que van contra su propia especie y casi podría decirse que contra toda la vida; se trata de políticos, empresarios y asesinos diversos que atentan contra el respeto a la dignidad humana. A partir de esto es que se lleva a cabo un proceso de domesticación, que consigue su objetivo cuando no se reconoce en el "yo" siempre a "otro" y viceversa, que nos compromete en una relación ética. Se trata de la fundación de una estética desde arriba - en función de la lógica imperial- que está fundamentada en ilusiones bancarias, en tanto que otorgan valor a lo inexistente y lucran con el sufrimiento de los más.

Dado lo anterior, se recurre a la propuesta de Mandoki que nos invita a pensar una estética desde abajo, desde el cuerpo mismo que reconozca las necesidades vitales del otro y sea capaz de escuchar su lamento, o mejor aún, evitarlo. En clave analéctica ha de decirse: atender al otro cuando soy con-vocado, cuando este se revela ante mí. Pero la revelación no es una manifestación necesaria, solo se sitúa ante quien ve, quien escucha, quien siente en genera. Es el momento en que se in-corpora al otro y se lo trae hacia uno mismo, porque es solo desde ahí, desde la sensibilidad desde abajo que se manifiesta el amor y la responsabilidad por el otro. En suma, solo quien se ha logrado configurar como otro es apto para el amor hacia lo real y no un amante de las ilusiones de mercado que traduce su acción mínima en el consumo. La religión que convirtió a Dios en dinero se llama Capitalismo, pero siguiendo a Levinas se ha de recordar que Dios está manifestándose en el cruce entre las miradas que garantizan simultáneamente sus existencias, como dos yo que se pueden reconocer como otro.

\section{Conclusiones}

Una analéctica del lamento reconoce esta relación desde el más allá (anó) (Dussel, 2011) pues refiere que el logos viene desde el más allá, es decir, desde lo otro, desde la exterioridad y no desde lo mismo. La ana-dialéctica, entonces, no puede prescindir de una actitud ética intersubjetiva, pues no puede surgir más que del lugar de los oprimidos, nos permite entender cuando el otro pide pan, cuando se lamenta por no tenerlo y con ello reconoce una exigencia, una que él entiende, aunque no esté necesariamente dicha. Los matices de esta propuesta nos conminan a entender en el otro una parte del yo, no plantearse así desde la diferencia, sino desde la dis-tinción (Dussel, 2011). En su lamento - y por consecuencia en su reclamo- el oprimido exige vivir, tiene el mismo derecho como todos los demás. El pobre, la violentada y el torturado claman justicia; ese clamor debe ser recogido por el mesías que estará dispuesto a jugarse la propia vida para hacer cumplir las demandas vitales de los negados. Gracias a su entendimiento analéctico podrá transformar la realidad, no hacía lo mismo, sino mediante la inclusión del otro.

¿Cómo empezar entonces a reflexionar sobre el lamento? El recorrido no es simple y tampoco alentador, sin embargo, bajo un espíritu analéctico podría decirse que la vía más idónea sería la de comenzar por los lamentos particulares que demandan atención: los pobres, las mujeres asesinadas y los torturados, entre otros; es decir, por una galería de víctimas que reclaman atención y la salida de un sistema de muerte administrado por una anestésica como fundamento de la necroestética que confunde a la sensibilidad humana con el sueño de lo trivial. Este paso inicial hacia el reconocimiento del lamento, es la punta de iceberg que se requiere para avanzar hacia la profundidad de los siguientes estadios que tengan su destino final en la praxis transformadora. 


\section{Referencias bibliográficas}

- Benjamin, W. (2016). Estética y política. Buenos Aires: Las cuarenta.

- Dussel, E. (2011). Filosofía de la liberación. México: FCE.

- Dussel, E. (2016). 14 tesis de ética. Hacia la esencia del pensamiento crítico. México: Trotta.

- Freire, P. (2016). Pedagogía del oprimido. México: Siglo XXI.

- Galeano, E. (2016). Memoria del fuego. 1. Los nacimientos. México: Gandhi.

- Mandoki, K. (2013). El indispensable exceso de a estética. México: Siglo XXI.

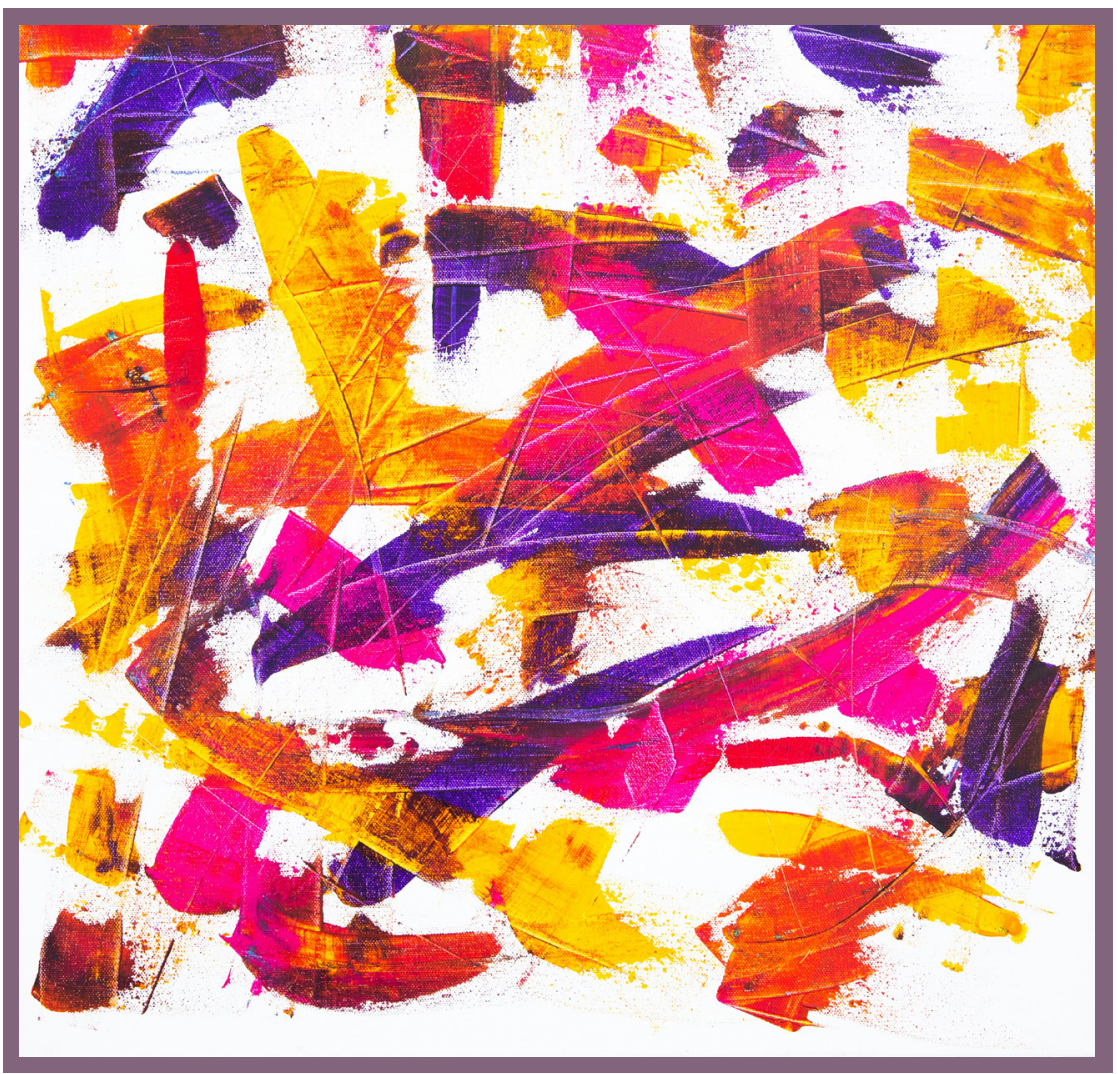

Arte de Markus Spike Alan Quezada Figueroa Universidad de Guanajuato Miembro de la Asociación Mexicana de Estudios en Estética y de la Asociación de Filosofía y Liberación Docente en la Escuela Nacional de Danza Folklórica del INBA ORCID. 0000-0003-2764-9785 filosofialan@gmail.com 